\title{
BC1 Regulation of Metabotropic Glutamate Receptor-Mediated Neuronal Excitability
}

\author{
Jun Zhong, ${ }^{1 \star}$ Shih-Chieh Chuang, ${ }^{1,2 \star}$ Riccardo Bianchi, ${ }^{1,2}$ Wangfa Zhao, ${ }^{1,2}$ Heekyung Lee, ${ }^{1,2}$ André A. Fenton, ${ }^{1,2}$ \\ Robert K. S. Wong, ${ }^{1,2,3}$ and Henri Tiedge $\mathrm{e}^{1,2,3}$ \\ ${ }^{1}$ The Robert F. Furchgott Center for Neural and Behavioral Science, Department of Physiology and Pharmacology, ${ }^{2}$ Program in Neural and Behavioral \\ Science, and ${ }^{3}$ Department of Neurology, State University of New York, Health Science Center at Brooklyn, Brooklyn, New York 11203
}

Regulatory RNAs have been suggested to contribute to the control of gene expression in eukaryotes. Brain cytoplasmic (BC) RNAs are regulatory RNAs that control translation initiation. We now report that neuronal BC1 RNA plays an instrumental role in the proteinsynthesis-dependent implementation of neuronal excitation-repression equilibria. BC1 repression counter-regulates translational stimulation resulting from synaptic activation of group I metabotropic glutamate receptors (mGluRs). Absence of BC1 RNA precipitates plasticity dysregulation in the form of neuronal hyperexcitability, elicited by group I mGluR-stimulated translation and signaled through the mitogen-activated protein kinase kinase/extracellular signal-regulated kinase pathway. Dysregulation of group I mGluR function in the absence of BC1 RNA gives rise to abnormal brain function. Cortical EEG recordings from freely moving $\mathrm{BC}^{-I-}$ animals show that group I mGluR-mediated oscillations in the gamma frequency range are significantly elevated. When subjected to sensory stimulation, these animals display an acute group I mGluR-dependent propensity for convulsive seizures. Inadequate RNA control in neurons is thus causally linked to heightened group I mGluR-stimulated translation, neuronal hyperexcitability, heightened gamma band oscillations, and epileptogenesis. These data highlight the significance of small RNA control in neuronal plasticity.

\section{Introduction}

Regulatory RNAs have been implicated in the control of gene expression in the mammalian CNS (Barciszewski and Erdmann, 2003; Cao et al., 2006). Dendritic brain cytoplasmic (BC) RNAs are translational repressors (Wang et al., 2002, 2005) that have been suggested to operate as modulators of local protein synthesis at the synapse (Wang and Tiedge, 2004; Kindler et al., 2005). Translational control of gene expression in synaptodendritic microdomains is considered critical for the development and longterm plasticity of synaptic connections and, therefore, for the expression of higher brain functions that rely on such plasticity (Huber et al., 2000; Eberwine et al., 2001; Kindler et al., 2005; Bassell and Twiss, 2006; Grossman et al., 2006; Pfeiffer and Huber, 2006; Dahm et al., 2007).

Local translation of synaptic mRNAs may be triggered by synaptic activity and other physiological stimuli (Job and Eberwine,

\footnotetext{
Received Aug. 14, 2008; revised April 8, 2009; accepted July 1, 2009.

This work was supported in part by the FRAXA Research Foundation (R.K.S.W.), National Science Foundation Grant I0S-0725001 (A.A.F.), and National Institutes of Health Grants NS057839 (A.A.F.), NS035481 (R.K.S.W.), and NS046769 (H.T.). J.Z. was a Building Interdisciplinary Research Careers in Women's Health scholar sponsored by National Institutes of Health Grant HD43428. We thank Dr. Jürgen Brosius (University of Münster School of Medicine, Münster, Germany) for $\mathrm{BC}^{-/-}$animals, Dr. Michael Tranfaglia (FRAXA Research Foundation, Newburyport, MA) for MPEP, and colleagues at the Robert F. Furchgott Center for advice and discussion. Statistical consultation was provided by Dr. Jeremy Weedon at the State University of New York Brooklyn Scientific Computing Center.

*J.Z. and S.C.-C. contributed equally to this work.

Correspondence should be addressed to either Henri Tiedge or Jun Zhong, The Robert F. Furchgott Center for Neural and Behavioral Science, Department of Physiology and Pharmacology, State University of New York, Health Science Center at Brooklyn, 450 Clarkson Avenue, Brooklyn, NY 11203, E-mail: htiedge@downstate.edu or jzhong@downstate.edu.

DOI:10.1523/JNEUROSCI.3893-08.2009

Copyright $\odot 2009$ Society for Neuroscience $\quad$ 0270-6474/09/299977-10\$15.00/0
}

2001; Kindler et al., 2005; Dahm et al., 2007). Although the nature and mode of action of synaptic translational modulators have remained elusive until recently, it now appears that most, if not all, of those modulators are repressors (Kindler et al., 2005; Tiedge, 2005). Dendritic BC1 RNA represses protein synthesis by targeting the translation pathway at the level of initiation (Wang et al., 2002, 2005). Translational repression is achieved by preventing assembly of $48 \mathrm{~S}$ initiation complexes; this inhibition is mediated by interactions of BC1 RNA with eukaryotic initiation factor $4 \mathrm{~A}(\mathrm{eIF} 4 \mathrm{~A})$ and poly(A) binding protein (Wang et al., 2002, 2005; Kondrashov et al., 2005). By targeting the catalytic activity of eIF4A (Lin et al., 2008), BC1 RNA inhibits unwinding of $5^{\prime}$ untranslated regions (UTRs) and thus prevents recruitment of small ribosomal subunits to the $5^{\prime}$ ends of such mRNAs (Pestova et al., 2007).

Improved organism-environment interactions, e.g., enhanced curiosity-driven behavioral activities, have been advanced as some of the evolutionary benefits of RNA-controlled local translation in neurons (Lewejohann et al., 2004; Cao et al., 2006). However, local translation, unless adequately controlled, may result in the inappropriate or premature synthesis of proteins, which may in turn cause dysregulation of synaptic function, precipitating synaptic hyperexcitability and vulnerability to epileptogenesis (Merlin et al., 1998; Musumeci et al., 2000; Chuang et al., 2005; McNamara et al., 2006).

We report here that non-protein-coding BC1 RNA is essential for the maintenance of excitation-repression balances at the synapse. We show that $\mathrm{BC} 1 \mathrm{RNA}$ represses the synthesis of some synaptic proteins [postsynaptic density 95 (PSD-95) and fragile X mental retardation protein (FMRP)] that is stimulated by activa- 
tion of group I metabotropic glutamate receptors (mGluRs). Signaling through group I mGluRs has been implicated previously in long-term synaptic modulation (Huber et al., 2000; Weiler et al., 2004). We now report that regulation of group I mGluR responses by BC1 RNA is essential for neuronal excitationrepression homeostasis because its absence unleashes group I mGluR-stimulated, translation-dependent neuronal hyperexcitability in vitro and excessive group I mGluR-dependent brain activity in vivo. Our data illustrate the functional significance of $\mathrm{BC1}$ RNA as a regulatory constraint in the group I mGluRstimulated translation pathway.

\section{Materials and Methods}

Animals. $\mathrm{BC1}^{-1-}$ mice (lines 13 and 15; mixed C57BL/6J and $129 \times 1 / \mathrm{SvJ}$ background) were obtained from Dr. Jürgen Brosius (University of Münster School of Medicine, Münster, Germany). The two lines were separately established from independent mutant embryonic stem cell lines, as described previously (Skryabin et al., 2003). Both lines were used in the experiments described here. Wild-type (WT) C57BL/6J and $129 \times 1 /$ SvJ mice (The Jackson Laboratory) were crossed to generate control animals for $\mathrm{BC1}^{-1-}$ animals. Unless stated otherwise, animals were used at an age of $18-21 \mathrm{~d}$.

Work with vertebrate animals was in accordance with the Public Health Service Policy on Humane Care and Use of Laboratory Animals and was approved by the State University of New York Brooklyn Institutional Animal Care and Use Committee.

Hippocampal slice preparations. Transverse hippocampal slices (400 $\mu \mathrm{m}$ ) were prepared as described previously (Lee et al., 2002) and placed in an interface recording chamber (Fine Science Tools). Artificial CSF (ACSF) contained the following (in $\mathrm{mM}$ ): $124 \mathrm{NaCl}, 5 \mathrm{KCl}, 1.6 \mathrm{MgCl}_{2}, 2$ $\mathrm{CaCl}_{2}, 26 \mathrm{NaHCO}_{3}$, and $10 \mathrm{D}$-glucose. Slices were continuously perfused with ACSF bubbled with $95 \% \mathrm{O}_{2} / 5 \% \mathrm{CO}_{2}$ and maintained at $33-35^{\circ} \mathrm{C}$, $\mathrm{pH} 7.4$.

(RS)-3,5-Dihydroxyphenylglycine stimulation and Western blot analysis. Hippocampal slices were transferred to a holding chamber filled with ACSF and incubated at $32.5^{\circ} \mathrm{C}$ for $1 \mathrm{~h}$. (RS)-3,5-Dihydroxyphenylglycine (DHPG) was added directly into the holding chamber to a final concentration of $100 \mu \mathrm{M}$. After $30 \mathrm{~min}$ of DHPG exposure, slices were collected and snap frozen on dry ice. Frozen sample was stored at $-80^{\circ} \mathrm{C}$.

DHPG-stimulated and control samples were sonicated in ice-cold homogenization buffer containing the following: $320 \mathrm{~mm}$ sucrose, $10 \mathrm{~mm}$ HEPES, pH 7.4, 2 mM EDTA, 1 mM EGTA, 1 mm NaF, protease inhibitors $(20 \mu \mathrm{g} / \mathrm{ml}$ aprotinin, $20 \mu \mathrm{g} / \mathrm{ml}$ leupeptin, $20 \mu \mathrm{g} / \mathrm{ml}$ pepstatin $\mathrm{A}$, and 1 $\mathrm{mm}$ PMSF), and phosphatase inhibitors ( $1 \mathrm{~mm} \mathrm{Na}_{3} \mathrm{VO}_{4}, 2.5 \mathrm{~mm}$ $\mathrm{Na}_{4} \mathrm{P}_{2} \mathrm{O}_{7}$, and $1 \mathrm{~mm} \beta$-glycerophosphate). Homogenates were mixed with detergents (final concentrations: $0.1 \%$ SDS, $0.5 \%$ deoxycholate, and $1 \% \mathrm{NP}-40$ ) and left on ice for $30 \mathrm{~min}$. The suspension was cleared by centrifugation. Lysates were aliquoted and stored at $-80^{\circ} \mathrm{C}$.

One aliquot was used to determine protein concentration using the BCA method (Fisher Scientific). Before electrophoresis, slice lysates were mixed with $2 \times$ SDS sample buffer $(20 \%$ glycerol, $10 \%$ $\beta$-mercaptoethanol, $4 \%$ SDS, and $125 \mathrm{~mm}$ Tris- $\mathrm{HCl}, \mathrm{pH}$ 6.8) and boiled for $5 \mathrm{~min}$. Samples were resolved by electrophoresis on 10\% SDS-PAGE gels (Novex Tris-glycine; Invitrogen) and transferred to nitrocellulose membranes (Mini Trans-Blot; Bio-Rad). Membranes were probed with antibodies, using the ECL method for detection (LumiGLO; Cell Signaling Technology). Antibodies against FMRP, PSD-95, and $\alpha$-tubulin were from Millipore Corporation. The $\alpha$-tubulin signal was used to normalize FMRP and PSD-95 signals in Western blot analyses. The antiphospho-extracellular signal-regulated kinase 1/2 (ERK1/2) antibody was from Cell Signaling Technology. Data were quantified using NIH ImageJ software.

Electrophysiological recordings. Slices were allowed to recover from the isolation procedure for at least $1.5 \mathrm{~h}$. Intracellular recordings were performed in CA3 pyramidal cells using an Axoclamp 2A amplifier (Molecular Devices). Electrodes were pulled with thin-walled glass tubing (World Precision Instruments) and had resistances of 30-50 $\mathrm{M} \Omega$ when filled with potassium acetate $(2 \mathrm{M})$. Voltage signals were displayed on an oscilloscope (DSO 400; Gould Instruments) and digitized and stored in an Intel Pentium-based computer using a Digidata 1322A converter controlled by pClamp 8 software (Molecular Devices).

A "blind" approach was adopted for these experiments. Recordings and data analysis were performed by different experimenters (S.-C.C. and R.B.). R.B. was blind to the genotype of the datasets, and genotypes were revealed only after completion of data analysis.

Pharmacological agents. Bicuculline (Bic) $(50 \mu \mathrm{M})$ was continuously perfused in the bath solution to elicit baseline discharge activities in mouse hippocampal slices. The mGluR1-selective antagonist LY367385 [(S)-(+)- $\alpha$-amino-4-carboxy-2-methylbenzeneacetic acid] $(50 \mu \mathrm{M})$, mGluR5-selective antagonist 2-methyl-6-(phenylethynyl)pyridine hydrochloride (MPEP) $(50 \mu \mathrm{M})$, and the translation inhibitor anisomycin $(15-20 \mu \mathrm{M})$ were obtained from Tocris Bioscience. The mitogenactivated protein kinase kinase 1/2 (MEK1/2) inhibitors PD98059 [2(2-amino-3-methyoxyphenyl)-4H-1-benzopyran-4-one] $(50 \mu \mathrm{M})$ and U0126 [1,4-diamino-2,3-dicyano-1,4-bis(o-aminophenylmercapto)butadiene] $(20 \mu \mathrm{M})$ and the mammalian target of rapamycin (mTOR) inhibitor rapamycin $(1 \mu \mathrm{M})$ were also obtained from Tocris Bioscience. Bicuculline and other chemicals were purchased from Sigma. All agents were stored in stock solutions at $-80^{\circ} \mathrm{C}$ for no more than $1-2$ weeks and were diluted into ACSF at the indicated final concentrations at the time of the experiments.

Data analysis. The durations of individual synchronized discharges were measured from the beginning of the first action potential to the repolarization of the last action potential of the discharge. Membrane potentials were kept within a few millivolts throughout the experiment. Frequency histograms included the durations of all synchronized discharges that were recorded in 6 min periods for each slice under the respective experimental conditions. Based on the distribution of the synchronized discharge durations shown previously by Chuang et al. (2005, their Fig. 1Dbi), "short" and "long" bursts refer to events shorter and longer, respectively, than $1.5 \mathrm{~s}$. All frequency histogram distributions were fitted with second-order Gaussian functions. Two positive peaks in the first derivative of the Gaussian fits indicated the appearance of a second, distinct peak at burst durations $>1.5$ s. Clampfit (Molecular Devices) and SigmaPlot (SPSS) software were used for data analysis, and SPSS software was used for statistical analysis.

Cortical electroencephalograms. The procedure for recording the epidural cortical electroencephalogram (EEG) was adapted from Wenzel et al. (2001). Detailed EEG methods are described in the supplemental data (available at www.jneurosci.org as supplemental material). The EEG was recorded while the animal moved freely in its home cage. The method was adapted from single-unit and local-field potential recording techniques (Fenton et al., 2000; Olypher et al., 2006). Recordings of baseline epidural EEG, EEG after administration of MPEP and anisomycin, and statistical methods are described in the supplemental data (available at www. jneurosci.org as supplemental material).

Auditory stimulation in vivo. Epileptogenic susceptibility to auditory stimuli was ascertained as described previously (Yan et al., 2004). In brief, 18- to 21 -d-old mice were placed in a plastic cage equipped with a $120 \mathrm{~dB}$ personal alarm device (TBO-Tech) mounted under a Styrofoam cage cover. Mice were subjected to auditory stimulation for $15 \mathrm{~min}$, and videos were recorded with a SONY digital camcorder. Video recordings were analyzed in slow motion by the experimenter and, independently, by a second person who was not cognizant of the animals' genotypes. The following parameters were scored: time to onset of uncontrolled running, time to onset of seizure, fraction of animals undergoing seizures (including clonic and tonic components, status epilepticus), and lethality. Onset of seizure was defined as the moment at which an animal collapsed in convulsion.

To examine protein-synthesis dependence of audiogenic seizures, $\mathrm{BCl}^{-1-}$ mice were injected intraperitoneally with $75 \mathrm{mg} / \mathrm{kg}$ anisomycin $1 \mathrm{~h}$ before auditory stimulation. This dose was within a range from 50 to $150 \mathrm{mg} / \mathrm{kg}$, which has been shown previously to be effective in blocking protein synthesis in brain (Lattal and Abel, 2004; Cai et al., 2006).

For experiments with the mGluR5 antagonist MPEP (obtained from Dr. Michael Tranfaglia, FRAXA Research Foundation, New- 
buryport, MA, or from Tocris Bioscience), each litter of animals was divided into two groups. Animals in one group were injected intraperitoneally with $50 \mu \mathrm{l}$ of $0.9 \% \mathrm{NaCl}$ (saline), whereas animals in the second group were injected with $50 \mu \mathrm{l}$ of saline containing MPEP at concentrations indicated. MPEP solutions were freshly prepared. Auditory stimulation was given $30 \mathrm{~min}$ after injections.

MEK1/2 inhibitor SL327 ( $\alpha$-[amino[(4-aminophenyl)thio]methylene]-2(trifluoromethyl)benzeneacetonitrile) (Tocris Bioscience) was dissolved in DMSO and administered through intraperitoneal injection as described previously (Atkins et al., 1998). SL327 was freshly prepared and injected at $100 \mathrm{mg} / \mathrm{kg}$ intraperitoneally $1 \mathrm{~h}$ before auditory stimulation. The dosage used was based on previous work (Atkins et al., 1998) that established effectiveness and lack of side effects. Littermate control animals were injected with vehicle (DMSO) at equal volumes.

\section{Results}

\section{Synthesis of synaptic proteins PSD-95 and FMRP is controlled by $\mathrm{BC} 1$ translational repression}

BC1 RNA has been shown to repress translation of reporter mRNAs in model systems (Wang et al., 2002, 2005). We now asked whether BC1 RNA controls synthesis of synaptic proteins in neurons. Activation of group I mGluRs is known to stimulate local translation of synaptic mRNAs (Weiler and Greenough, 1993; Merlin et al., 1998; Huber et al., 2000; Bear et al., 2004; Shin et al., 2004). Does BC1 RNA function as a translational repressor in group I mGluR-dependent protein synthesis? To address this question, we asked whether such synthesis is dysregulated in the absence of BC1 RNA. We focused on PSD-95 and FMRP because synthesis of these synaptic proteins has been shown previously to be stimulated by group I mGluR activation (Weiler et al., 1997; Todd et al., 2003).

We stimulated hippocampal slices, prepared from $B C 1^{-/-}$ and WT animals, with the group I mGluR agonist DHPG (Fig. 1). In WT hippocampal preparations, activation of group I mGluRs stimulated synthesis of PSD-95 and FMRP, as reported previously. Such stimulation was significantly elevated in hippocampal slices prepared from $B C 1^{-/-}$animals (Fig. 1). DHPG-mediated translational stimulation of PSD-95 was increased by $100 \%$ (i.e., twofold) in $B C 1^{-/-}$preparations compared with WT preparations. DHPG-mediated translational stimulation of FMRP was increased by $67 \%$ in $B C 1^{-1-}$ preparations (Fig. 1). In contrast, basal levels of FMRP (in the absence of DHPG stimulation) were indistinguishable in $\mathrm{BC1}^{-/-}$and WT preparations (supplemental Fig. 1, available at www.jneurosci.org as supplemental material).

DHPG-stimulated synthesis of both PSD-95 and FMRP was blocked by addition of $20 \mu \mathrm{M}$ anisomycin $45 \mathrm{~min}$ before DHPG treatment. In the presence of anisomycin, the average relative signal intensity for PSD-95 in DHPG-treated preparations was $100 \pm 3 \%$ (i.e., unchanged; $p=0.93 ; n=8$ ) compared with nontreated preparations (supplemental Fig. 2, available at www.jneurosci.org as supplemental material). For FMRP, the average relative signal intensity (DHPG-treated vs nontreated) was $85 \pm 2 \%(p<0.001 ; n=8)$. It is concluded that the elevated levels of PSD-95 and FMRP, observed after group I mGluR activation, are dependent on new protein synthesis.

The combined data suggest that, for the synthesis of PSD-95 and FMRP, BC1 RNA functions as a repressive counterbalance to group I mGluR-mediated translational stimulation.

\footnotetext{
Absence of $\mathrm{BC} 1 \mathrm{RNA}$ gives rise to neuronal hyperexcitability Excessive translation will cause disturbances in synaptic protein repertoires, which may entail dysregulated synaptic transmission and synaptic hyperexcitability (Merlin et al., 1998; Huber et al.,
}

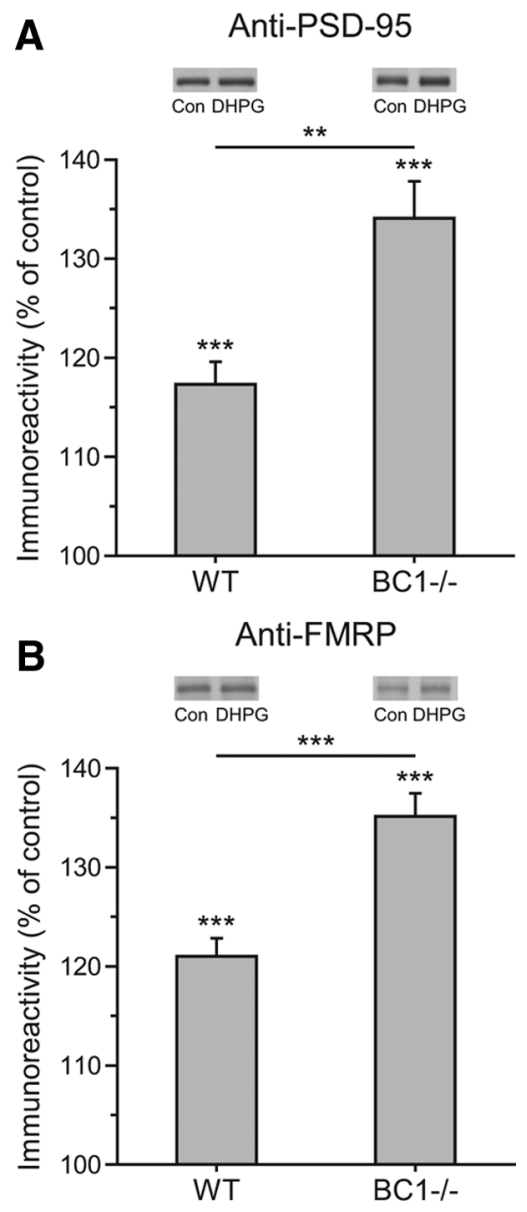

Figure 1. Lack of $B C 1$ RNA causes upregulation of mGluR-stimulated translation. $\boldsymbol{A}$, Western blot analysis of hippocampal slice lysates probed with an antibody against PSD-95. Hippocampal slices obtained from WT or $B C 1^{-/-}$animals were incubated in ACSF with or without $100 \mu \mathrm{M}$ DHPG for 30 min. DHPG exposure increased expression levels of PSD-95 in samples from WT and $B C 1^{-1-}$ animals ( $p<0.001$, compared with basal expression levels, Student's $t$ test), and the increase in $B C 1^{-1-}$ preparations (34 $\pm 4 \% ; n=8$ ) was significantly larger than that in WT preparations ( $17 \pm 2 \% ; n=8 ; p<0.01$, Student's $t$ test). $\boldsymbol{B}$, Western blot analysis of hippocampal slice lysates probed with an antibody against FMRP. FMRP expression levels were increased by DHPG in WT and $B C 1^{-/-}$slices ( $p<0.001$, compared with basal levels, Student's $t$ test). Similar to the PSD-95 increase shown in $A$, the increase in $B C 1^{-1-}$ preparations ( $35 \pm$ $2 \% ; n=8$ ) was significant larger than that in WT preparations $(21 \pm 2 \% ; n=8 ; p<0.001$, Student's $t$ test). Error bars indicate SEM, and $n$ indicates number of animals used. Representative Western blot results are shown above each bar diagram. Asterisks above bars indicate significant differences compared with basal levels (not DHPG-stimulated, normalized to $100 \%$ ), and asterisks above brackets indicate significant differences between animal groups. Con, Control. In this and all subsequent figures, levels of significance are defined as follows: ${ }^{*} p<0.05,{ }^{* *} p<0.01,{ }^{* * *} p<0.001$.

2000; Chuang et al., 2005; McNamara et al., 2006). Having shown that $\mathrm{BC} 1 \mathrm{RNA}$ negatively regulates group I mGluR-stimulated translation in hippocampus, we now probed neuronal hyperexcitability in hippocampal neurons.

We examined functional consequences of synaptic activation of group I mGluRs by recording synchronized discharges of glutamatergic principal neurons in hippocampal slices. Synaptic activation can be induced by application of bicuculline, a $\mathrm{GABA}_{\mathrm{A}}$ receptor antagonist (Chuang et al., 2005). Intracellular recordings were performed in CA3 pyramidal cells of hippocampal slice preparations from $B C 1^{-/-}$and WT animals. In WT preparations, application of bicuculline elicited short $(<1.5 \mathrm{~s})$ synchronized discharges (Fig. 2, left). Such short discharges remained stable over the entire recording period (of up to $4 \mathrm{~h}$ ). 
In $B C 1^{-/-}$hippocampal slices, in contrast, bicuculline elicited short synchronized discharges that, over a period of time, invariably transformed into recurrent prolonged synchronized discharges (average duration, $5.475 \pm 0.124 \mathrm{~s}$ ) (Fig. 2 , right). These prolonged synchronized bursts were coincidental with field potential deflections and with discharges in all other cells recorded (data not shown). The development of prolonged synchronized discharges, such as recorded in $B C 1^{-/-}$preparations, are the manifestation of a plasticity change that results in neuronal hyperexcitability (Chuang et al., 2005). These prolonged discharges were never observed in WT preparations (Fig. 2). We conclude that lack of BC1 RNA in hippocampus results in neuronal hyperexcitability and a heightened propensity for prolonged synchronized discharges.

Modification of population firing in the presence of bicuculline was not associated with changes in the passive properties of recorded neurons. In a total of five cells from $\mathrm{BC1}^{-/-}$preparations, input resistance (measured from responses to 0.2 $\mathrm{nA}, 100 \mathrm{~ms}$ intracellular current pulses injected at $-65 \mathrm{mV}$ in the absence of spontaneous firing) was $35.2 \pm 2.9$ and $33.8 \pm 2.2 \mathrm{M} \Omega$ at 20 and $120 \mathrm{~min}$ bicuculline, respectively $(p=0.73)$. The data suggest that emergence of prolonged synchronized discharges in bicuculline-treated slices is not accompanied by changes in passive membrane properties of the recorded neuron. It is possible that the mGluRinduced hyperexcitability is elicited via the activation of a voltage-gated cationic current $\left(I_{\mathrm{mGluR}(\mathrm{V})}\right)$ (Chuang et al., 2001).

\section{$B C 1^{-/-}$neuronal hyperexcitability requires group I mGluR signaling} We next examined whether neuronal hyperexcitability that is observed in the absence of $\mathrm{BC} 1$ RNA requires signaling through group I mGluRs. We used blockers of both mGluR subtypes that constitute group I: LY367385, an antagonist specific for mGluR1, and MPEP, an antagonist specific for mGluR5. Prolonged synchronized discharges were elicited in $B C 1^{-/-}$hippocampal slices as described above. Subsequent to the appearance of such prolonged discharges, slices were perfused with LY367385 or MPEP.

With either antagonist, prolonged synchronized discharges vanished within 30 min, and only short synchronized discharges, undistinguishable from those elicited in slices from WT animals, were recorded henceforth (Fig. 3A). Thus, an-
A

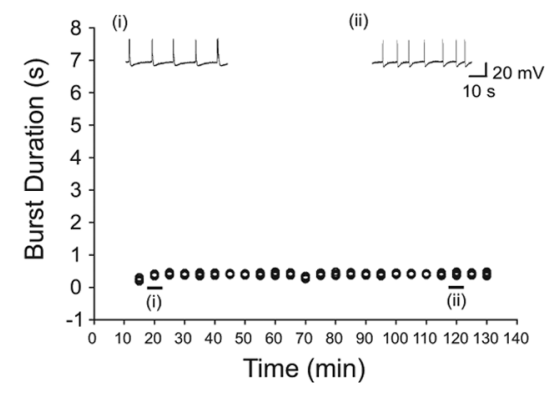

B
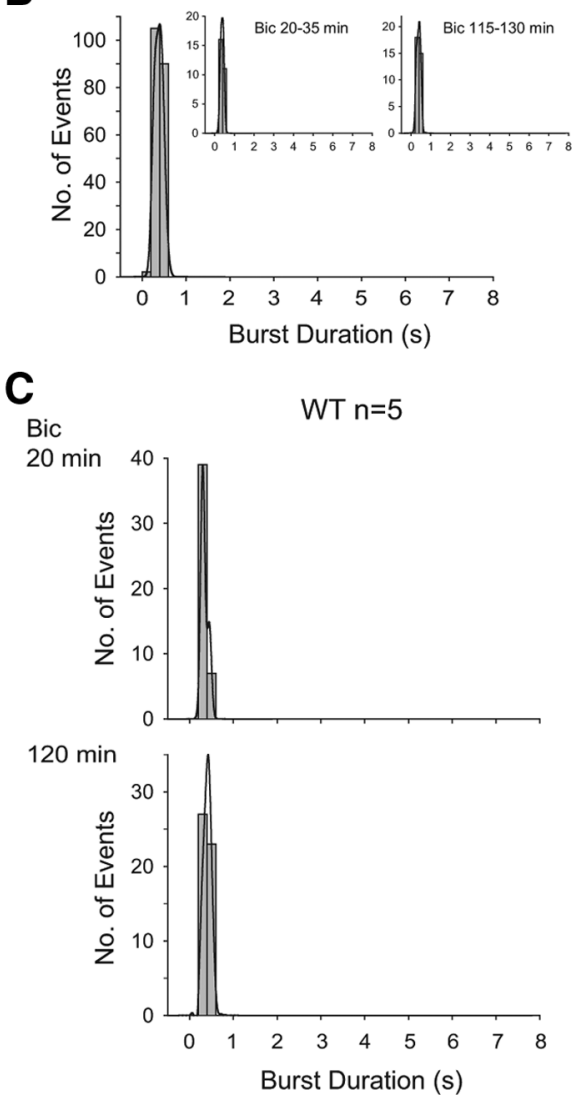

BC1-/-
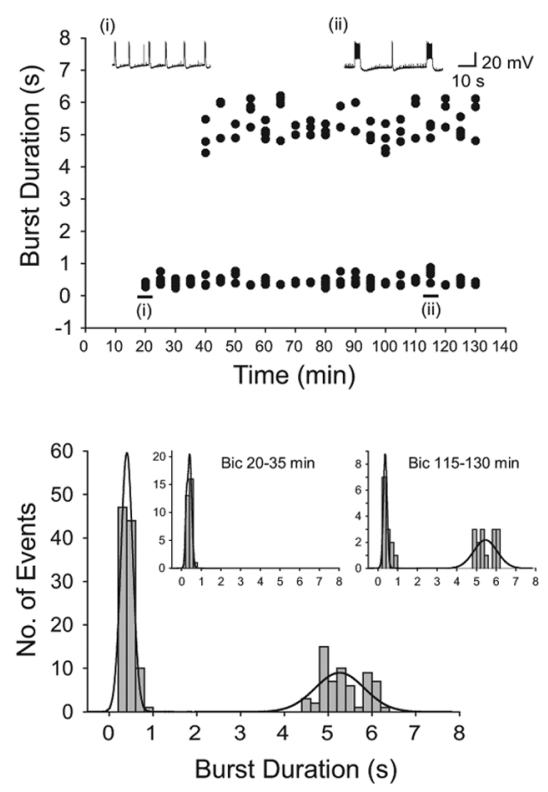

BC1-/- $n=6$
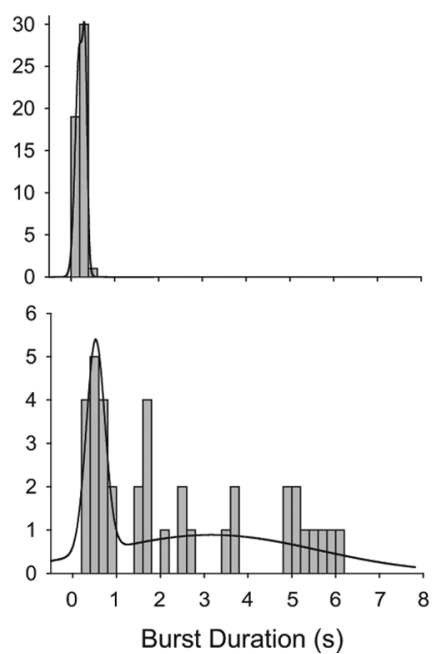

Figure 2. Activation of glutamatergic synapses induces prolonged synchronized discharges in $\mathrm{BC}^{-/-}$hippocampal slices. Results from WT slices are shown on the left, and results from $\mathrm{BC}^{-/-}$slices are shown on the right. Bic (50 $\mu \mathrm{m}$ ) was applied at $t=0$. $A$, The graphs plot the duration of each population burst recorded in the cells over time. In WT preparations, only short-duration bursts $\left(<1.5 \mathrm{~s}\right.$ ) were induced by bicuculline and persisted for $>2 \mathrm{~h}$. In the $B C 1^{-1-}$ preparation, after an initial period during which only short duration bursts were recorded, discharges of prolonged duration $(\sim 5 \mathrm{~s})$ appeared $\sim 40$ min after application of bicuculline. Insets $\boldsymbol{i}$ and $\boldsymbol{i i}$ show the intracellular recording of rhythmic bursts of action potentials obtained in CA3 pyramidal cells at the times indicated. Resting membrane potential: WT at 20 and 120 $\mathrm{min} B i c,-63$ and $-61 \mathrm{mV}$, respectively; $B C^{-/-}$at 20 and $120 \mathrm{~min} \mathrm{Bic},-64$ and $-62 \mathrm{mV}$, respectively. Input resistance: WT at 20 and $120 \mathrm{~min} \mathrm{Bic,} 35$ and $33 \mathrm{M} \Omega$, respectively; $B \mathrm{C}^{-1-}$ at 20 and $120 \mathrm{~min} \mathrm{Bic,} 30$ and $31 \mathrm{M} \Omega$, respectively. $\boldsymbol{B}$, Frequency histograms of burst durations for the experiments shown in $\boldsymbol{A}$. Second-order Gaussian function fits of frequency histogram distributions are shown in all plots. Insets show average burst durations in the interval $20-35 \mathrm{~min}$ for WT (mean \pm SEM, $0.391 \pm 0.008 \mathrm{~s} ; n=27)$ and $B C 1^{-/-}(0.420 \pm 0.018 \mathrm{~s} ; n=30)$ and in the interval $115-130 \mathrm{~min}$ for WT $(0.407 \pm 0.006 \mathrm{~s} ; n=33)$ and $B C 1^{-/-}(3.154 \pm 0.485 \mathrm{~s} ; n=28)$. Prolongation of average burst duration in the $B C 1^{-1-}$ $115-130 \mathrm{~min}$ interval was attributable to the appearance of a distinct group of long bursts $(5.475 \pm 0.124 \mathrm{~s} ; n=15)$. Burst duration in the $\mathrm{BC}^{-1-}$ preparation was significantly longer at $115-130 \mathrm{~min}$ of bicuculline than at $20-35 \mathrm{~min}$ in the same slice (Student's $t$ test for unpaired data, $p<0.001$ ) and also significantly longer than at $115-130$ min in a WT preparation $(p<0.001)$. For the WT preparation, burst duration did not change significantly over the recording period (Student's test for unpaired data, $p=0.115)$. C, Summary frequency histograms recorded in five WT and six $B C 1^{-1-}$ slice preparations (1 slice per animal) at the times indicated. Bursts of prolonged duration ( $>1.5 \mathrm{~s}$ ) were recorded in all $B C 1^{-1-}$ hippocampal slices after 120 min of bicuculline but never in WT preparations. 
A
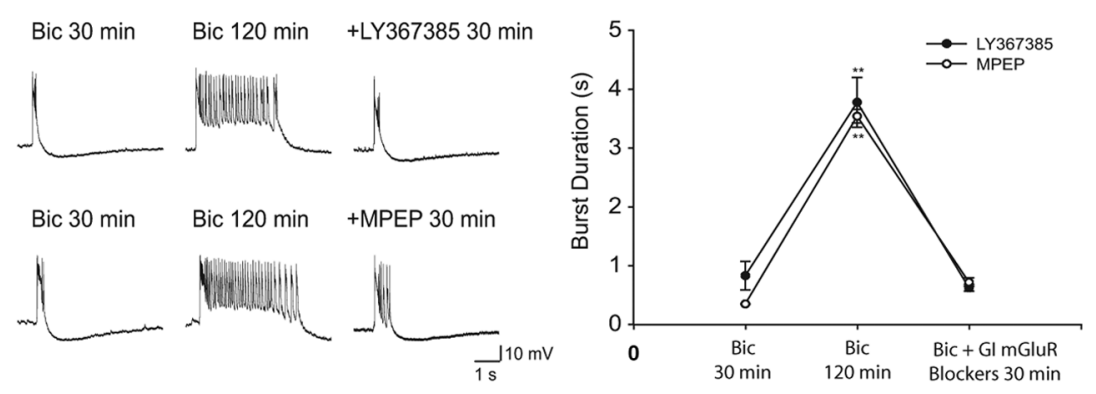

B
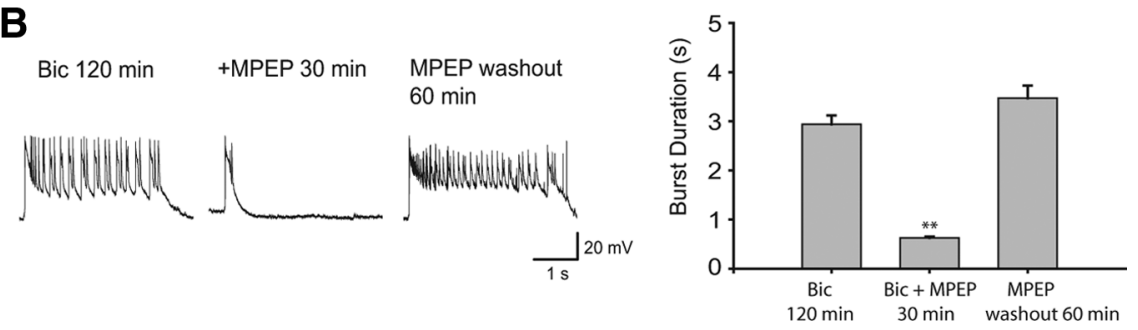

Figure 3. Group I mGluR signaling is required to trigger neuronal hyperexcitability elicited in the absence of BC1 RNA. A, Prolonged synchronized discharges in hippocampal slices recorded at $120 \mathrm{~min}$ after perfusion with bicuculline were suppressed by the mGluR1 antagonist LY367385 (50 $\mu \mathrm{m}$, top left) and the mGluR5 antagonist MPEP (50 $\mu \mathrm{m}$, bottom left). Right panel shows a summary plot of average burst durations at times indicated. Extended bicuculline exposure prolonged bursts (Bic $30 \mathrm{~min}, 0.830 \pm$ $0.241 \mathrm{~s}$; Bic $120 \mathrm{~min}, 3.776 \pm 0.423 \mathrm{~s} ; n=3$; filled circles; two-way ANOVA, post hoc Newman-Keuls test, $p<0.01)$. These prolonged bursts were subsequently shortened by LY367385, within $30 \mathrm{~min}$, to $0.622 \pm 0.058 \mathrm{~s}(p<0.01)$. Similarly, bursts of $0.347 \pm 0.006 \mathrm{~s}$ (Bic $30 \mathrm{~min} ; n=3$; open circles), after having been prolonged by bicuculline to $3.538 \pm 0.117 \mathrm{~s}$ (Bic $120 \mathrm{~min} ; n=$ 3 ; open circles; $p<0.01$ ), were shortened by MPEP within $30 \mathrm{~min}$ to $0.718 \pm 0.073 \mathrm{~s}(p<0.01)$. Statistical analysis revealed no significant differences between durations of bursts recorded in the presence of antagonists (LY367385 or MPEP) and those recorded at 30 min bicuculline. $\boldsymbol{B}$, Suppression of prolonged synchronized discharges by mGluR5 antagonist MPEP is reversible. Prolonged synchronized discharges recorded $120 \mathrm{~min}$ after bicuculline application were completely suppressed 30 min after application of $50 \mu \mathrm{M}$ MPEP (left). Prolonged synchronized discharges reappeared within 60 min after MPEP washout. The bar graph on the right shows the summary data of burst durations recorded at $120 \mathrm{~min}$ in Bic $(2.935 \pm 0.185$ $s ; n=4), 30 \mathrm{~min}$ Bic plus MPEP $(0.628 \pm 0.026 s ; p<0.01)$, and $60 \mathrm{~min}$ after MPEP washout $(3.470 \pm 0.257 s ; p=0.1)$. Error bars indicate SEM.

tagonists of both group I mGluR subtypes effectively suppressed prolonged synchronized discharges in $B C 1^{-/-}$hippocampal slices. In contrast, durations of short synchronized discharges recorded after application of LY367385 or MPEP were not significantly different from those recorded $30 \mathrm{~min}$ after application of bicuculline (Fig. $3 A$ ), a finding consistent with previous observations that durations of bicuculline-induced short discharges in WT preparations are not affected by group I mGluR antagonists (Chuang et al., 2005). The data suggest that the observed shortening of prolonged discharges is attributable to general suppressant effects of group I mGluR antagonists on cellular excitability. Of note, when MPEP was washed out from the bath solution, prolonged synchronized discharges reappeared within $60 \mathrm{~min}$ of MPEP withdrawal (Fig. 3B), indicating that the action of the mGluR5 antagonist was fully reversible.

The results indicate that signaling through both group I mGluR subtypes is necessary for the manifestation of neuronal hyperexcitability triggered in the absence of BC1 RNA. The suppression of prolonged synchronized discharges by mGluR5 or mGluR1 blockers (MPEP or LY367385, respectively) is consistent with that observed in another form of translation-dependent plasticity-long-term depression (LTD) - that is induced by group I mGluR activation. Specifically, after LTD induction, application of a group I mGluR blocker reversed the depressed synaptic response and restored it to the original (larger) amplitude observed before LTD induction (Watabe et al., 2002). Thus, in both cases, the persistent expression of plastic changes induced by group I mGluR signaling is itself dependent on sustained group I mGluR activation.

\section{Neuronal hyperexcitability in the absence of BC1 RNA is dependent on new protein synthesis}

If the observed neuronal hyperexcitability results from excessive group I mGluRdependent translation, such hyperexcitability should be blocked by a general translational inhibitor. We therefore asked whether the prolonged synchronized discharges that are generated in $B C 1^{-/-}$preparations can be suppressed by the protein synthesis inhibitor anisomycin. Bicuculline was applied to $B C 1^{-/-}$ hippocampal slices preincubated with anisomycin (Merlin et al., 1998; Chuang et al., 2005). Short synchronized discharges were elicited, as described above. However, in contrast to the results obtained with $\mathrm{BCl}^{-/-}$slices in the absence of protein synthesis inhibitors, these short discharges never transformed into prolonged synchronized discharges (Fig. $4 A, B)$. Conversely, once induced in $B C 1^{-/-}$, prolonged synchronized discharges were not affected by anisomycin (Fig. 4C). The data suggest that the effect of anisomycin is not mediated through a nonspecific suppression of single-cell excitability. We conclude that the synaptic induction of prolonged synchronized discharges in $B C 1^{-1-} \mathrm{CA} 3$ cells is dependent on de novo protein synthesis.

\section{$\mathrm{BC1}^{-/-}$neuronal hyperexcitability requires signaling} through the MEK-ERK pathway

Group I mGluRs couple to the translational machinery by recruiting one or both of two main signal transduction modules, the Akt-mTOR module and the MEK-ERK module (Pfeiffer and Huber, 2006). Which of these signaling modules couples to BC1 control?

Working with the mTOR inhibitor rapamycin, we found that signaling through the Akt-mTOR module is not required for the induction of group I mGluR-mediated prolonged synchronized discharges (supplemental Fig. 3, available at www.jneurosci.org as supplemental material). In contrast, when ERK1/2 phosphorylation was blocked, neuronal hyperexcitability was no longer inducible because only short synchronized discharges could be elicited by bicuculline in $B C 1^{-1-}$ preparations (Fig. $4 A, B$ ). The MEK1/2 inhibitor PD98059 completely suppressed the appearance of prolonged synchronized discharges in $\mathrm{BC1}^{-/-}$preparations, indicating that signaling through the MEK-ERK pathway is required for the manifestation of neuronal hyperexcitability in the absence of BC1 RNA.

Phosphorylation of ERK1/2, in response to activation of group I mGluRs by DHPG, occurred at similar levels in $B C 1^{-1-}$ and WT preparations (supplemental Fig. 4, available at www. jneurosci.org as supplemental material). This result indicates that signaling through the MEK-ERK pathway is not altered in the absence of $\mathrm{BC1}$ RNA, in agreement with the notion that $\mathrm{BC} 1$ 
RNA functions downstream of group I mGluR-MEK-ERK signaling.

\section{Lack of BC1 RNA triggers epileptogenic vulnerability in vivo}

BC1 RNA, our data show, controls group I mGluR-dependent translation and is required for the maintenance of an appropriate excitability tone at the synapse. Because absence of BC1 RNA results in neuronal hyperexcitability, the question arises whether such hyperexcitability results in a heightened epileptogenic propensity that can be diagnosed in vivo. To probe for epileptogenic susceptibility, we subjected $B C 1^{-/-}$animals to auditory stimulation (Musumeci et al., 2000; Chen and Toth, 2001; Yan et al., 2005).

When exposed to a $120 \mathrm{~dB}$ alarm, $B C 1^{-/-}$animals typically displayed initial signs of epileptic activity in the form of frenzied, "out-of-control" running and jumping. (Videos showing the responses of $\mathrm{BC}^{-/-}$animals with and without MPEP treatment are available on request.) This frenetic activity was undirected (i.e., not an escape reaction) and was the first indication of imminent convulsive seizures. A high percentage of $B C 1^{-1-}$ animals (84\%) succumbed to generalized clonic-tonic convulsive seizures within 2 min after onset of the alarm (Fig. 5A). Most of these animals, however, recovered from such seizures after $\sim 1 \mathrm{~min}$; they did not usually display additional epileptic symptoms during the remainder of the 15 min auditory stimulation period. A minority of $B C 1^{-/-}$animals $(23 \%)$ died while undergoing audiogenic seizures (Fig. 5A).

We next examined whether seizure vulnerability in $B C 1^{-/-}$ animals is dependent on protein synthesis. $B C 1^{-/-}$mice were injected with $75 \mathrm{mg} / \mathrm{kg}$ anisomycin $1 \mathrm{~h}$ before auditory stimulation. Of 20 animals tested, only two developed convulsive seizures, and none died (Fig. 5A). These data are in agreement with the data obtained in vitro (Fig. 4) and support the notion that group I mGluR-dependent translation is required for the manifestation of epileptogenic responses in $\mathrm{BC1}^{-/-}$animals.

A key feature of synaptic dysregulation caused by the absence of BC1 RNA is its dependence on group I mGluR activation. To test whether this is also the case for epileptogenic responses in vivo, we administered the mGluR5 antagonist MPEP $30 \mathrm{~min}$ before auditory stimulation. MPEP-injected (40 $\mathrm{mg} / \mathrm{kg}$, i.p.) $B C 1^{-/-}$animals failed to display any signs of epileptic activities, such as uncontrolled running, convulsive seizures, or audiogenic lethality, during the entire $15 \mathrm{~min}$ period of auditory stimulation (Fig. $5 B$ ). MPEP-injected $B C 1^{-1-}$ animals typically gathered at the perimeter of the cage after onset of the auditory stimulus and did not display unusual locomotion or other activity during the remainder of the 15 min stimulation period. Thus, the mGluR5 antagonist MPEP effectively represses epileptogenic responses in $B C 1^{-/-}$animals in vivo.

We further applied the MEK1/2 inhibitor SL327 to $B C 1^{-/-}$ animals in vivo. Figure $5 C$ shows that injection of SL327 $60 \mathrm{~min}$ before auditory stimulation significantly reduced incidences of seizures and death. MEK-ERK signaling is evidently required for the auditory induction of epileptogenic responses in $\mathrm{BC1}^{-/-}$animals. The combined results point to the MEK-ERK cascade as central in coupling group I mGluR signaling to BC1-controlled pathways. Because MEK1/2 and group I mGluR inhibitors were applied 30-60 min before exposure to auditory stimulation, the data suggest that the susceptibility of $\mathrm{BC1}^{-/-}$animals to epileptogenic responses resulted from excessive consequences of group I mGluR stimulation, signaled through the MEK-ERK pathway, that have occurred before auditory stimulation.

\section{EEG recordings reveal excessive group I mGluR-dependent gamma oscillations in $\mathrm{BC1}^{-/-}$animals}

Our data indicate that inadequate $\mathrm{BC} 1$ control precipitates neuronal hyperexcitability and a propensity for epileptogenic responses. These results prompted us to ask whether consequences of $\mathrm{BC1}^{-1-}$ synaptic dysregulation can also be observed in stimulation-independent settings. Thus, to examine whether altered neural activities can be detected in freely moving animals, we performed cortical EEG recordings in mutant and WT animals (Fig. 6A).

$\mathrm{BC}^{-/-}$and WT EEG recordings are presented as power spectra in Figure $6 \mathrm{~B}$. The most salient feature of $B C 1^{-1-}$ EEG power spectra was a prominent peak in the gamma frequency band. A zero-derivative, local maximum at $57 \mathrm{~Hz}$ defined the $B C 1^{-1-}$ gamma peak. This gamma peak was distinct in the $B C 1^{-1-}$ EEG. It was absent in the WT EEG because a zero derivative was not defined in this case. On average, the gamma peak in the $B C 1^{-/-}$ EEG was $121 \pm 51 \%$ above the calculated baseline power at the peak frequency. Spectral power in the $47-67 \mathrm{~Hz}$ frequency band, centered on the gamma-peak frequency, was significantly increased in the $B C 1^{-/-} \operatorname{EEG}\left(t_{(13)}=2.2 ; p=0.047\right)$. In contrast, 


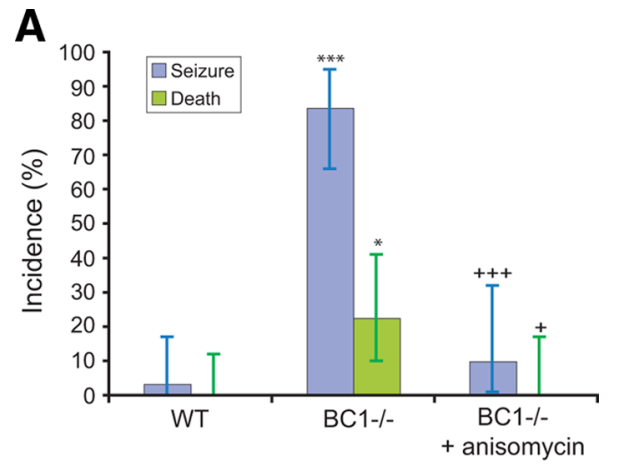

B
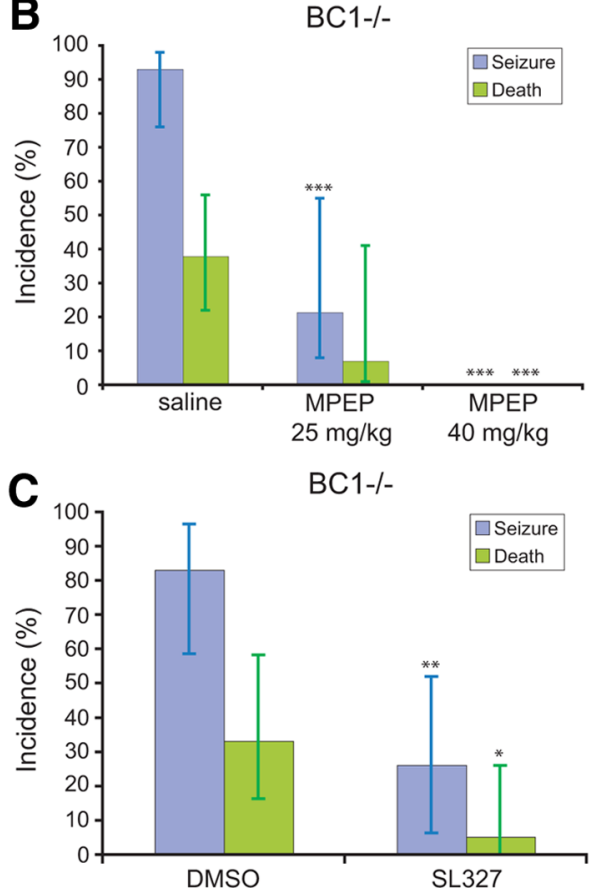

Figure 5. $B C 1^{-1-}$ animals are acutely susceptible to auditory stimuli. $A$, Lack of BC1 RNA significantly increased propensity for audiogenic seizures (exact logistic regression stratified by litter; ${ }^{* * *} p<0.001$, compared with WT). $B C 1^{-/-}$animals also had a significantly higher audiogenic lethality incidence compared with WT $\left({ }^{*} p=0.012\right)$. Injection of $75 \mathrm{mg} / \mathrm{kg}$ anisomycin intraperitoneally $1 \mathrm{~h}$ before onset of auditory stimuli prevented seizures $\left({ }^{++}{ }^{+} p<\right.$ $0.001)$ and death ( $\left.{ }^{+} p=0.045\right)$ in $B C 1^{-1-}$ animals. WT, $n=30 ; B C 1^{-1-}, n=31 ; B C 1^{-1-}$ injected with anisomycin, $n=20 . B$, Convulsive seizures and lethality were effectively prevented in $\mathrm{BC}^{-/-}$animals by intraperitoneal injection of MPEP at $40 \mathrm{mg} / \mathrm{kg} 30 \mathrm{~min}$ before onset of auditory stimuli. Compared with a saline-injected group, the $40 \mathrm{mg} / \mathrm{kg}$ MPEP group had a significant lower incidence of seizures (generalized linear model; $p<0.0001$ ) and lethality $(p<0.0001$ ). At $25 \mathrm{mg} / \mathrm{kg}$ MPEP, seizure incidence was significantly reduced ( $p=$ 0.0002 ). Saline control group, $n=29 ; 25 \mathrm{mg} / \mathrm{kg}$ MPEP group, $n=14 ; 40 \mathrm{mg} / \mathrm{kg}$ MPEP group, $n=10$. C, Injection of selective MEK1/2 inhibitor SL327 (100 mg/kg in DMSO, i.p.) $60 \mathrm{~min}$ before auditory stimulation significantly reduced incidence of seizures $(p<0.01$; exact logistic regression stratified by litter) and death $(p<0.05)$ in $B C 1^{-/-}$animals $(n=18)$. Littermate control animals were injected with equal amounts of vehicle DMSO $(n=19)$. Error bars represent $95 \%$ confidence intervals (Cumming et al., 2007). $n$ indicates the number of animals used.

increases of $\mathrm{BC1}^{-/-}$EEG power over WT EEG power in other frequency bands did not reach statistical significance.

To examine whether the increase of gamma power in the absence of BC1 RNA was maintained by ongoing protein synthesis, we injected $B C 1^{-/-}$animals $(75 \mathrm{mg} / \mathrm{kg}$, i.p.) with anisomycin during EEG recordings. Although spectral power was reduced at all frequencies, anisomycin was notable in abolishing the mutant animal gamma peak (supplemental Fig. 5, available at www.jneurosci.org as supplemental material). Specifically, after anisomycin injection, a zero-derivative local maximum near the preinjection gamma peak could no longer be defined in any mutant mice. The data suggest that the manifestation of excessive gamma frequency cortical oscillatory activities in $\mathrm{BC1}^{-/-}$animals is dependent on protein synthesis.

Previous work indicated that synchronized cortical gammaband oscillations can be sustained by group I mGluR activation (Whittington et al., 1995). Does enhanced group I mGluR signaling underlie excessive gamma oscillations in $\mathrm{BC1}^{-/-}$animals? We addressed this question by blocking mGluR5 with MPEP. Individual mutant spectrograms revealed that, within a few minutes after administration, MPEP abolished excessive gammafrequency oscillations in $B C 1^{-/-}$EEG (Fig. 6C). In contrast, WT spectrograms failed to reveal any obvious MPEP-induced EEG changes (Fig. 6C). Group-averaged power spectra showed that, in the knock-out, MPEP affected the overall profile of the spectra and specifically eliminated the gamma peak as a zero-derivative local maximum in the gamma frequency band, which was no longer defined (Fig. 6D). In contrast, MPEP did not affect gamma power in WT power spectra (Fig. $6 D$ ). Thus, excessive gamma oscillations in $B C 1^{-1-}$ animals are mediated by mGluR5 activation.

MPEP also reduced power in the theta and beta-alpha bands in $B C 1^{-/-}$animals (Fig. 6C) but not in WT animals (Fig. 6D). A higher dependence of theta oscillations on group I mGluR activation in $\mathrm{BC1}^{-/-}$animals is intriguing because theta oscillations have been associated with locomotion and exploration (Vanderwolf, 1969; Buzsáki, 2002), which is compromised in $B C 1^{-/-}$ animals (Lewejohann et al., 2004).

\section{Discussion}

Small RNA control in neurons

RNA control is a fundamental component in the regulation of gene expression in eukaryotes (Barciszewski and Erdmann, 2003; Mattick, 2003; Brosius, 2005). It is thought that, in neurons, small regulatory RNAs have evolved to serve as mediators of organismenvironment interactions (Cao et al., 2006). Our data show that synaptodendritic BC1 RNA, in the capacity of a translational repressor, functions in group I mGluR-stimulated translational pathways. $\mathrm{BC} 1$ control maintains a scalable excitability tone because inadequate $\mathrm{BC} 1$ control causes functional dysregulation that manifests as neuronal hyperexcitability, excessive cortical gamma-frequency oscillations, and heightened epileptogenic susceptibility in vitro and in vivo. Each of these phenotypical manifestations in the absence of BC1 RNA was reversed by inhibition of protein synthesis, by inhibition of group I mGluR activation, or by inhibition of ERK-MEK signaling. The combined data support a model in which BC1 RNA acts as a repressor of group I mGluR-mediated neuronal protein synthesis. Although the present work does not attempt to localize $\mathrm{BC} 1$ function to synaptodendritic domains (and does therefore not rule out somatic contributions), the results are consistent with a synaptodendritic role in view of previous data that have shown BC1 RNA to be the most prominent RNA component in postsynaptic microdomains (Chicurel et al., 1993).

We propose that local excitation-repression equilibria are in part maintained by a functional yin-yang interplay between group I mGluR responses and the action of BC1 RNA. Signaling through group I mGluRs, increasing evidence suggests, stimulates synaptic protein synthesis (Weiler and Greenough, 1993; Merlin et al., 1998; Huber et al., 2000; Bear et al., 2004; Shin et al., 2004). BC1 RNA is a translational repressor that targets initiation (Wang et al., 2002, 2005; Lin et al., 2008) and therefore operates downstream from group I mGluRs, in a 
position that would allow it to control signaling through this pathway. Absence of BC1 RNA results in increased group I mGluR stimulation of PSD-95 and FMRP synthesis. Thus, in these cases, BC1-mediated translational repression functions as a counterbalance to group I mGluR-mediated translational stimulation. It is interesting to note that a neuronal translational repressor, BC1 RNA, will repress translation of another translational repressor, FMRP, in a scenario that will likely add to the complexity of local regulatory output.

The data on group I mGluR-stimulated translation obtained in $\mathrm{BCl}^{-/-}$preparations contrast those observed in preparations lacking FMRP. In the latter case, translation of PSD-95 is not stimulated by group I mGluR activation (data not shown and Todd et al., 2003). Lack of FMRP may preclude group I mGluRmediated translational stimulation because (1) basal translational output is elevated to a point at which it is no longer stimulated by group I mGluR activation (Qin et al., 2005; Nosyreva and Huber, 2006), and/or because (2) group I mGluR signaling itself is defective (Ronesi and Huber, 2008). It appears that BC1 RNA and FMRP, which both target translation regulated through group I mGluR-ERKMEK signaling, use non-identical mechanisms in their repression strategies.

Synchronized gamma oscillations are generated by interneuron networks that entrain principal cells, and group I mGluR activation is required for the synchronization of cortical networks at gamma frequencies (Whittington et al., 1995). Cortical EEG data now show that excessive gamma oscillations, driven by mGluR5 activation, occur in $B C 1^{-/-}$animals. Synchronized gamma oscillations in the $30-80 \mathrm{~Hz}$ frequency range (Uhlhaas and Singer, 2006) have been implicated in cortical mechanisms of perception and cognition because they appear to underlie local and long-range neural network coordination. Excessive gamma oscillations, such as observed in the absence of $\mathrm{BC} 1$ RNA, may affect long-range network connectivity in brain (Uhlhaas and Singer, 2006).

Suppression of gamma band oscillations by MPEP is an example of a response shared by other mGluR-induced long-lasting events, including mGluR agonist-induced prolonged discharges and LTD. In either case, expression of the maintained responses is reversibly suppressed by either mGluR 1 or mGluR 5 antagonists (Merlin and Wong, 1997; Watabe et al., 2002). It appears that, after induction of plastic changes by group I mGluR activation, the continued expression of such changes is also dependent on group I mGluR signaling.

A

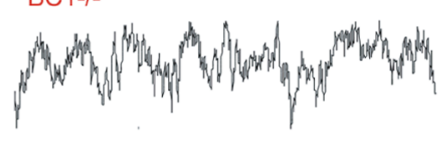

WT

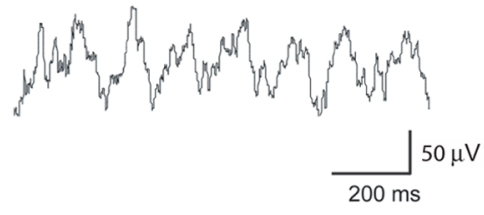

BC1-/-

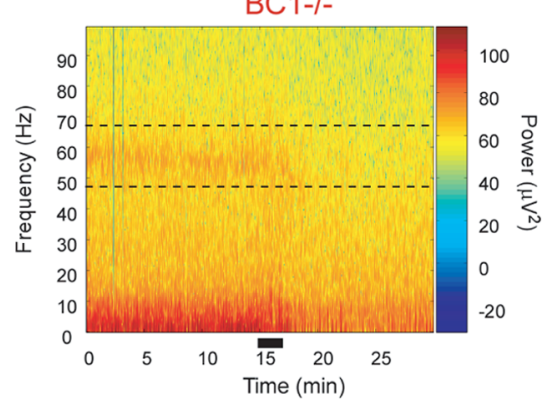

D

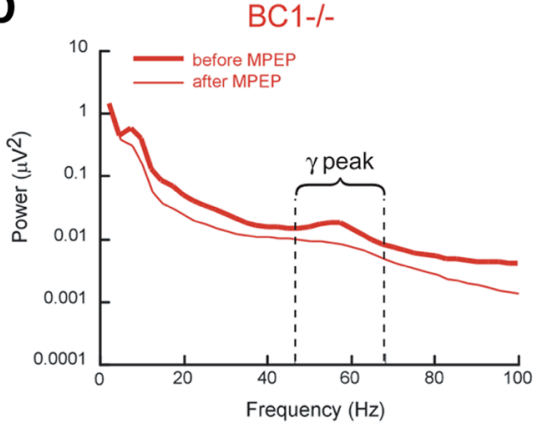

B

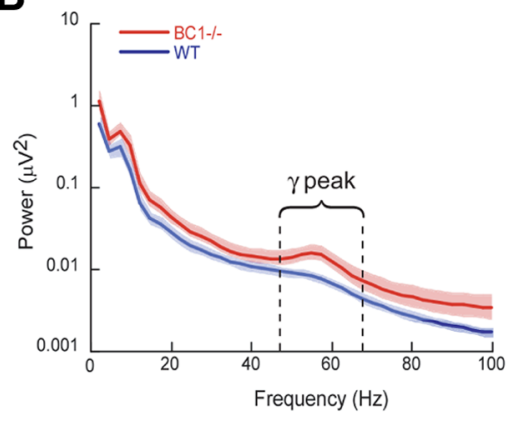

WT

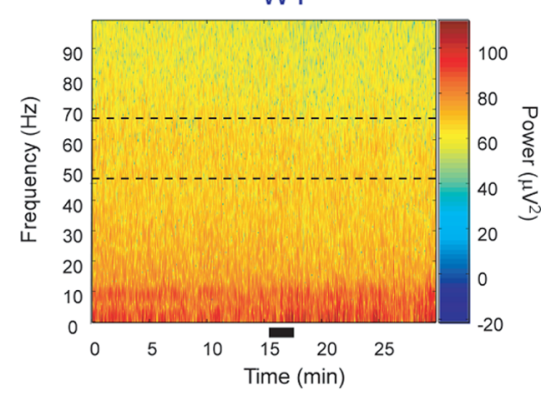

WT

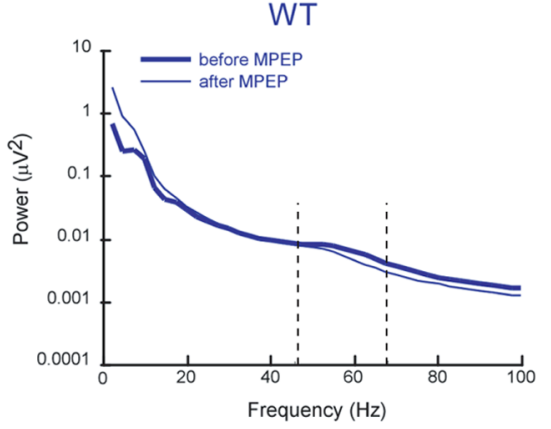

Figure 6. EEG recordings reveal increased mGluR-mediated gamma oscillations in $B C 1^{-/-}$animals. $A$, Epidural EEG recordings from a $B C 1^{-/-}$and a WT animal with recognizable theta and gamma oscillations. $B$, Average $B C 1^{-/-}$(red line) and WT (blue line) power spectra, with pink and light blue shades indicating respective SEM. The $B C 1^{-1-}$ EEG had generally higher power, but the most salient difference was a prominent gamma peak centered at $57 \mathrm{~Hz} . \mathrm{BC}^{-1-}$ power was significantly higher between 47 and $67 \mathrm{~Hz}$, the range centered on the gamma peak $\left(t_{(13)}=2.2 ; p=0.047\right)$. This range is illustrated by dashed lines. The differences between $\mathrm{BC}^{-1-}$ and WT EEG in the delta, theta, or alpha- beta frequency bands did not reach statistical significance $(p>0.05$ in each case). $\boldsymbol{C}, \boldsymbol{D}$, The mGluR5 antagonist MPEP was administered after $15 \mathrm{~min}$ of baseline recording. $\boldsymbol{C}$, Spectrograms from single experiments with a $\mathrm{BC}^{-/-}$and a WT mouse illustrate that the main effect of MPEP was to decrease power in the $B C 1^{-/-}$EEG in the range of the gamma peak. An effect of MPEP on the WT EEG was less apparent. The time of the administration is illustrated by the black bar. $D$, Treatment-averaged $B C 1^{-/-}$and WT power spectra quantify the effect of MPEP on the EEG. Power in the range of the gamma peak was significantly reduced by MPEP in the $B C 1^{-1-}$ EEG (red thin line; $t_{(4)}=3.08 ; p=0.03$ ) but did not change in the WT EEG (blue thin line; $t_{(2)}=0.99 ; p=0.43$ ). Power in the theta $\left(t_{(4)}=3.1 ; p=0.04\right)$, alpha- beta $\left(t_{(4)}=3.8 ; p=0.02\right)$, and full gamma $\left(t_{(4)}=3.1 ; p=0.036\right)$ bands was also reduced in the $B C 1^{-/}$EEG. In contrast, in the WT EEG, MPEP increased theta power $\left(t_{(2)}=4.3 ; p=0.05\right)$ and did not change power in the alpha-beta $\left(t_{(2)}=0.04 ; p=0.97\right)$ or gamma $\left(t_{(2)}=0.75\right.$; $p=0.52)$ bands. MPEP did not change delta power in $B C 1^{-1-}$ animals $\left(t_{(4)}=0.7 ; p=0.95\right)$ but increased power in the delta band of WT animals $\left(t_{(2)}=11.3 ; p=0.008\right)$.

\section{Neuronal translational repressors}

Like BC1 RNA, FMRP is a translational repressor that is functionally associated with group I mGluR-stimulated translation (Bear et al., 2004). Also similar to the BC1 system, absence of FMRP results in synaptic dysregulation in the form of hyperexcitability and epileptogenic susceptibility (Musumeci et al., 2000; Chuang et al., 2005). The overall functional output of the two repressors thus seems to be overlapping. This functional overlap is the result of distinct repression strategies that target different translation mechanisms. FMRP engages polyribosomes and therefore represses translation at a point subsequent to initiation (Ceman et 
al., 2003; Khandjian et al., 2004; Stefani et al., 2004; Davidovic et al., 2005). BC1 RNA, in contrast, is not associated with polyribosomes (Krichevsky and Kosik, 2001) because it represses translation at the level of initiation (Wang et al., 2002, 2005). A specific direct interaction between the two repressors (Zalfa et al., 2003) has not been confirmed (Wang et al., 2005; Iacoangeli et al., 2008).

The selectivity of a synaptic translational repressor will in part be determined by the complement of locally available mRNAs (Muslimov et al., 2006). A limited number of neuronal mRNAs have been validated as bona fide synaptodendritic, but the total repertoire of such mRNAs is likely diverse and synapseheterogeneous (Eberwine et al., 2002; Zhong et al., 2006). It is a hallmark of $\mathrm{BC} 1$ control that, as a general translational regulator that inhibits the helicase activity of eIF4A, it will target a subset of mRNAs that feature complex 5' UTRs (Lin et al., 2008). The extent to which an mRNA will require unwinding for efficient initiation is a function of the length and stability of its 5' UTR (Gray and Hentze, 1994; Dmitriev et al., 2003). The subset of neuronal mRNAs with such $5^{\prime}$ UTRs may in fact be rather small, although they appear to be highly represented among synaptically located mRNAs (A. Iacoangeli and $\mathrm{H}$. Tiedge, unpublished observation). The 5' UTRs of PSD-95 and Fmr1 mRNAs, encoding synaptic proteins, are longer and of higher stability than those of somatic representatives, such as glyceraldehyde-3-phosphate dehydrogenase mRNA, encoding a prototypical "housekeeping" enzyme. We posit that BC1 RNA, by virtue of its 5' UTR mRNA selectivity, is particularly well suited to engage mRNAs at the synapse.

Other work suggests that FMRP also targets a subgroup of neuronal mRNAs that are enriched at the synapse (Miyashiro et al., 2003). Although BC1 RNA and FMRP repress translation via different target recognition mechanisms, they engender common action in regulating group I mGluR function presumably because of (1) the availability of a subset of mRNAs that are targeted by both repressors and (2) the enrichment of this subset in synaptodendritic domains.

The functional interplay between a dendritic regulatory RNA and group I mGluRs represents a novel mode of translational control in neurons. The determinants of this interplay are molecular in nature, specified by $\mathrm{BC} 1$ interactions with the translation initiation machinery. The consequences of such interplay, however, transcend molecular mechanisms because they impact brain function and animal behavior. Because of the extensive distributions of BC1 RNA and of group I mGluRs in brain, BC1 control of group I mGluR-stimulated translation is expected to have widespread impact on brain function, as demonstrated by our data showing dysregulated cortical oscillatory activity and a propensity for convulsive seizures in $\mathrm{BC1}^{-/-}$animals. We submit that functional BC1-group I mGluR interactions serve as a substratum for diverse manifestations of neuronal plasticity and brain function.

\section{References}

Atkins CM, Selcher JC, Petraitis JJ, Trzaskos JM, Sweatt JD (1998) The MAPK cascade is required for mammalian associative learning. Nat Neurosci 1:602-609.

Barciszewski J, Erdmann VA, eds (2003) Noncoding RNAs: molecular biology and molecular medicine. Georgetown, TX: Landes Bioscience.

Bassell GJ, Twiss JL (2006) RNA exodus to Israel: RNA controlling function in the far reaches of the neuron. EMBO Rep 7:31-35.

Bear MF, Huber KM, Warren ST (2004) The mGluR theory of fragile X mental retardation. Trends Neurosci 27:370-377.

Brosius J (2005) Waste not, want not: transcript excess in multicellular eukaryotes. Trends Genet 21:287-288.
Buzsáki G (2002) Theta oscillations in the hippocampus. Neuron 33:325-340.

Cai WH, Blundell J, Han J, Greene RW, Powell CM (2006) Postreactivation glucocorticoids impair recall of established fear memory. J Neurosci 26:9560-9566.

Cao X, Yeo G, Muotri AR, Kuwabara T, Gage FH (2006) Noncoding RNAs in the mammalian central nervous system. Annu Rev Neurosci 29:77-103.

Ceman S, O’Donnell WT, Reed M, Patton S, Pohl J, Warren ST (2003) Phosphorylation influences the translation state of FMRP-associated polyribosomes. Hum Mol Genet 12:3295-3305.

Chen L, Toth M (2001) Fragile X mice develop sensory hyperreactivity to auditory stimuli. Neuroscience 103:1043-1050.

Chicurel ME, Terrian DM, Potter H (1993) mRNA at the synapse: analysis of a preparation enriched in hippocampal dendritic spines. J Neurosci 13:4054-4063.

Chuang SC, Bianchi R, Kim D, Shin HS, Wong RK (2001) Group I metabotropic glutamate receptors elicit epileptiform discharges in the hippocampus through PLC $\beta 1$ signaling. J Neurosci 21:6387-6394.

Chuang SC, Zhao W, Bauchwitz R, Yan Q, Bianchi R, Wong RK (2005) Prolonged epileptiform discharges induced by altered group I metabotropic glutamate receptor-mediated synaptic responses in hippocampal slices of a fragile X mouse model. J Neurosci 25:8048-8055.

Cumming G, Fidler F, Vaux DL (2007) Error bars in experimental biology. J Cell Biol 177:7-11.

Dahm R, Kiebler M, Macchi P (2007) RNA localisation in the nervous system. Semin Cell Dev Biol 18:216-223.

Davidovic L, Huot ME, Khandjian EW (2005) Lost once, the Fragile X Mental Retardation protein is now back onto brain polyribosomes. RNA Biol $2: 1-3$.

Dmitriev SE, Terenin IM, Dunaevsky YE, Merrick WC, Shatsky IN (2003) Assembly of $48 \mathrm{~S}$ translation initiation complexes from purified components with mRNAs that have some base pairing within their $5^{\prime}$ untranslated regions. Mol Cell Biol 23:8925-8933.

Eberwine J, Miyashiro K, Kacharmina JE, Job C (2001) Local translation of classes of mRNAs that are targeted to neuronal dendrites. Proc Natl Acad Sci U S A 98:7080-7085.

Eberwine J, Belt B, Kacharmina JE, Miyashiro K (2002) Analysis of subcellularly localized mRNAs using in situ hybridization, mRNA amplification, and expression profiling. Neurochem Res 27:1065-1077.

Fenton AA, Csizmadia G, Muller RU (2000) Conjoint control of hippocampal place cell firing by two visual stimuli. I. The effects of moving the stimuli on firing field positions. J Gen Physiol 116:191-209.

Gray NK, Hentze MW (1994) Regulation of protein synthesis by mRNA structure. Mol Biol Rep 19:195-200.

Grossman AW, Aldridge GM, Weiler IJ, Greenough WT (2006) Local protein synthesis and spine morphogenesis: Fragile X syndrome and beyond. J Neurosci 26:7151-7155.

Huber KM, Kayser MS, Bear MF (2000) Role for rapid dendritic protein synthesis in hippocampal mGluR-dependent long-term depression. Science 288:1254-1257.

Iacoangeli A, Rozhdestvensky TS, Dolzhanskaya N, Tournier B, Schütt J, Brosius J, Denman RB, Khandjian EW, Kindler S, Tiedge H (2008) On BC1 RNA and the fragile X mental retardation protein. Proc Natl Acad Sci U S A 105:734-739.

Job C, Eberwine J (2001) Localization and translation of mRNA in dendrites and axons. Nat Rev Neurosci 2:889-898.

Khandjian EW, Huot ME, Tremblay S, Davidovic L, Mazroui R, Bardoni B (2004) Biochemical evidence for the association of fragile X mental retardation protein with brain polyribosomal ribonucleoparticles. Proc Natl Acad Sci U S A 101:13357-13362.

Kindler S, Wang H, Richter D, Tiedge H (2005) RNA transport and local control of translation. Annu Rev Cell Dev Biol 21:223-245.

Kondrashov AV, Kiefmann M, Ebnet K, Khanam T, Muddashetty RS, Brosius J (2005) Inhibitory effect of naked neural BC1 RNA or BC200 RNA on eukaryotic in vitro translation systems is reversed by poly(A)-binding protein (PABP). J Mol Biol 353:88-103.

Krichevsky AM, Kosik KS (2001) Neuronal RNA granules: a link between RNA localization and stimulation-dependent translation. Neuron 32:683-696.

Lattal KM, Abel T (2004) Behavioral impairments caused by injections of the protein synthesis inhibitor anisomycin after contextual retrieval reverse with time. Proc Natl Acad Sci U S A 101:4667-4672. 
Lee AC, Wong RK, Chuang SC, Shin HS, Bianchi R (2002) Role of synaptic metabotropic glutamate receptors in epileptiform discharges in hippocampal slices. J Neurophysiol 88:1625-1633.

Lewejohann L, Skryabin BV, Sachser N, Prehn C, Heiduschka P, Thanos S, Jordan U, Dell'Omo G, Vyssotski AL, Pleskacheva MG, Lipp HP, Tiedge $\mathrm{H}$, Brosius J, Prior H (2004) Role of a neuronal small non-messenger RNA: behavioural alterations in BC1 RNA-deleted mice. Behav Brain Res 154:273-289.

Lin D, Pestova TV, Hellen CU, Tiedge H (2008) Translational control by a small RNA: dendritic BC1 RNA targets the eukaryotic initiation factor 4A helicase mechanism. Mol Cell Biol 28:3008-3019.

Mattick JS (2003) Challenging the dogma: the hidden layer of non-proteincoding RNAs in complex organisms. Bioessays 25:930-939.

McNamara JO, Huang YZ, Leonard AS (2006) Molecular signaling mechanisms underlying epileptogenesis. Sci STKE 2006:re12.

Merlin LR, Wong RK (1997) Role of group I metabotropic glutamate receptors in the patterning of epileptiform activities in vitro. J Neurophysiol 78:539-544.

Merlin LR, Bergold PJ, Wong RK (1998) Requirement of protein synthesis for group I mGluR-mediated induction of epileptiform discharges. J Neurophysiol 80:989-993.

Miyashiro KY, Beckel-Mitchener A, Purk TP, Becker KG, Barret T, Liu L, Carbonetto S, Weiler IJ, Greenough WT, Eberwine J (2003) RNA cargoes associating with FMRP reveal deficits in cellular functioning in Fmrl null mice. Neuron 37:417-431.

Muslimov IA, Iacoangeli A, Brosius J, Tiedge H (2006) Spatial codes in dendritic BC1 RNA. J Cell Biol 175:427-439.

Musumeci SA, Bosco P, Calabrese G, Bakker C, De Sarro GB, Elia M, Ferri R, Oostra BA (2000) Audiogenic seizures susceptibility in transgenic mice with fragile X syndrome. Epilepsia 41:19-23.

Nosyreva ED, Huber KM (2006) Metabotropic receptor-dependent longterm depression persists in the absence of protein synthesis in the mouse model of fragile X syndrome. J Neurophysiol 95:3291-3295.

Olypher AV, Klement D, Fenton AA (2006) Cognitive disorganization in hippocampus: a physiological model of the disorganization in psychosis. J Neurosci 26:158-168.

Pestova T, Lorsch JR, Hellen CUT (2007) The mechanism of translation initiation in eukaryotes. In: Translational control in biology and medicine (Mathews MB, Sonenberg N, Hershey JWB, eds), pp 87-128. Cold Spring Harbor, NY: Cold Spring Harbor Laboratory.

Pfeiffer BE, Huber KM (2006) Current advances in local protein synthesis and synaptic plasticity. J Neurosci 26:7147-7150

Qin M, Kang J, Burlin TV, Jiang C, Smith CB (2005) Postadolescent changes in regional cerebral protein synthesis: an in vivo study in the FMR1 null mouse. J Neurosci 25:5087-5095.

Ronesi JA, Huber KM (2008) Homer interactions are necessary for metabotropic glutamate receptor-induced long-term depression and translational activation. J Neurosci 28:543-547.

Shin CY, Kundel M, Wells DG (2004) Rapid, activity-induced increase in tissue plasminogen activator is mediated by metabotropic glutamate receptor-dependent mRNA translation. J Neurosci 24:9425-9433.

Skryabin BV, Sukonina V, Jordan U, Lewejohann L, Sachser N, Muslimov I, Tiedge H, Brosius J (2003) Neuronal untranslated BC1 RNA: targeted gene elimination in mice. Mol Cell Biol 23:6435-6441.
Stefani G, Fraser CE, Darnell JC, Darnell RB (2004) Fragile X mental retardation protein is associated with translating polyribosomes in neuronal cells. J Neurosci 24:7272-7276.

Tiedge H (2005) RNA reigns in neurons. Neuron 48:13-16.

Todd PK, Mack KJ, Malter JS (2003) The fragile X mental retardation protein is required for type-I metabotropic glutamate receptor-dependent translation of PSD-95. Proc Natl Acad Sci U S A 100:14374-14378.

Uhlhaas PJ, Singer W (2006) Neural synchrony in brain disorders: relevance for cognitive dysfunctions and pathophysiology. Neuron 52:155-168.

Vanderwolf CH (1969) Hippocampal electrical activity and voluntary movement in the rat. Electroencephalogr Clin Neurophysiol 26:407-418.

Wang H, Tiedge H (2004) Translational control at the synapse. Neuroscientist 10:456-466.

Wang H, Iacoangeli A, Popp S, Muslimov IA, Imataka H, Sonenberg N, Lomakin IB, Tiedge H (2002) Dendritic BC1 RNA: functional role in regulation of translation initiation. J Neurosci 22:10232-10241.

Wang H, Iacoangeli A, Lin D, Williams K, Denman RB, Hellen CU, Tiedge H (2005) Dendritic BC1 RNA in translational control mechanisms. J Cell Biol 171:811-821.

Watabe AM, Carlisle HJ, O’Dell TJ (2002) Postsynaptic induction and presynaptic expression of group $1 \mathrm{mGluR}$-dependent LTD in the hippocampal CA1 region. J Neurophysiol 87:1395-1403.

Weiler IJ, Greenough WT (1993) Metabotropic glutamate receptors trigger postsynaptic protein synthesis. Proc Natl Acad Sci U S A 90:7168-7171.

Weiler IJ, Irwin SA, Klintsova AY, Spencer CM, Brazelton AD, Miyashiro K, Comery TA, Patel B, Eberwine J, Greenough WT (1997) Fragile X mental retardation protein is translated near synapses in response to neurotransmitter activation. Proc Natl Acad Sci U S A 94:5395-5400.

Weiler IJ, Spangler CC, Klintsova AY, Grossman AW, Kim SH, BertainaAnglade V, Khaliq H, de Vries FE, Lambers FA, Hatia F, Base CK, Greenough WT (2004) Fragile X mental retardation protein is necessary for neurotransmitter-activated protein translation at synapses. Proc Natl Acad Sci U S A 101:17504-17509.

Wenzel HJ, Robbins CA, Tsai LH, Schwartzkroin PA (2001) Abnormal morphological and functional organization of the hippocampus in a p35 mutant model of cortical dysplasia associated with spontaneous seizures. J Neurosci 21:983-998.

Whittington MA, Traub RD, Jefferys JG (1995) Synchronized oscillations in interneuron networks driven by metabotropic glutamate receptor activation. Nature 373:612-615.

Yan QJ, Asafo-Adjei PK, Arnold HM, Brown RE, Bauchwitz RP (2004) A phenotypic and molecular characterization of the fmr1-tm1Cgr fragile $\mathrm{X}$ mouse. Genes Brain Behav 3:337-359.

Yan QJ, Rammal M, Tranfaglia M, Bauchwitz RP (2005) Suppression of two major Fragile X Syndrome mouse model phenotypes by the mGluR5 antagonist MPEP. Neuropharmacology 49:1053-1066.

Zalfa F, Giorgi M, Primerano B, Moro A, Di Penta A, Reis S, Oostra B, Bagni C (2003) The fragile X syndrome protein FMRP associates with BC1 RNA and regulates the translation of specific mRNAs at synapses. Cell 112:317-327.

Zhong J, Zhang T, Bloch LM (2006) Dendritic mRNAs encode diversified functionalities in hippocampal pyramidal neurons. BMC Neurosci 7:17. 